\title{
COVID-19 pandemic: Challenges Among Rising High School Seniors, Class of 2021, and Effect on Stress Regarding College Admissions
}

\author{
Sarab Anand ${ }^{1}$ and Dr. Triptish Bhatia ${ }^{1}$ \\ ${ }^{1}$ Blair Academy, Blairstown, New Jersey, USA
}

\section{ABSTRACT}

The high school Class of 2021, already facing challenges of their stressful junior year has had multiple changes to their academic routines, athletic \& extracurricular opportunities, and standardized testing amid the COVID-19 pandemic. With the lockdown, it is also facing unprecedented changes in the college admissions process.

This study was undertaken as a survey of rising seniors in US high schools to understand handling of academic challenges, students' stress regarding college admissions, changing landscape of the application cycle and attitudes towards strength of applications due to the pandemic. The survey was designed on Google Forms and was circulated among rising seniors through their schools as well as social media. The data was analyzed using descriptive and inferential statistics.

A total of 331 students responded, majority were females, white and from public schools. Significant stress regarding college admissions was reported by students (63.6\%) before pandemic and increase in stress (72.3\%) afterwards. About $75 \%$ had already taken ACT/SAT, the majority was not satisfied with their scores but $90 \%$ planned to re(take) despite colleges declaring a test optional process. $60 \%$ of participants with change in summer plans and $70 \%$ of students unable to visit colleges reported increase in stress. Level of access correlated with perceived support from college counselors $(\mathrm{r}=0.677)$ and uncertainty regarding financial aid and athletic scholarships contributed to stress.

Two broad themes emerged while studying COVID-19 related increase in stress levels and factors contributing to that change: uncertainty about one's own application strength and stress due to changes in institutional policies.

\section{Introduction}

In late 2019, a novel coronavirus strain, SARs-CoV-2, causing the highly communicable disease COVID-19, emerged in Wuhan, China and quickly spread across the world, necessitating social distancing to curb its spread. The Centers for Disease Control and Prevention (CDC) issued a warning on February 25th, 2020 to the nation's schools regarding the need to prepare for the expected disruption. (Lieberman, 2020, August 30) The importance of shutting down academic institutions to limit the spread of an infectious disease has been well documented in previous outbreaks, such as the 2009 H1N1 pandemic. (Chao, Halloran \& Longini, 2010)

In the United States, schools started a shift to remote learning, starting with a district in Washington state on March 5th. Within a span of three weeks, all US public schools and many independent schools nationwide closed, impacting over 50 million school-aged children. Concurrently, colleges and universities announced closing of campuses and a switch to an online format. As the number of US cases skyrocketed, it became clear that school closures would last for the rest of the 2019-20 academic year, causing an unprecedented disruption of education throughout the country, across all ages. (Decker, Peele \& Riser-Kositsky, 2020, July 1) 
The Class of 2021, already dealing with the academic challenges of junior year, are facing the changing landscape of the upcoming college admissions cycle amid the pandemic. Stress related to high school (HS) students before the COVID era has been well documented. A 2015 study of high school juniors found that "students experienced high levels of chronic stress, particularly in relation to academic performance and the college admissions process. (Bardi, Koone, Mewaldt \& O'Connor, 2011) The pressure to "secure admissions to stellar colleges" has been related to not only academics but also extracurricular activities. (Luthar \& Becker, 2002)

On the other hand, there is emerging data regarding the effects of the COVID pandemic on mental health of young people. A Chinese study of 4,000 students found that $26.6 \%$ of students had some level of anxiety about the pandemic, and depressive emotions were felt in $21 \%$ of students. (Chang, Yuan \& Wang, 2020)

While anxiety and stress in teenagers and young adults and their link to the college admissions process has been studied, and there is evidence of the pandemic's effects on mental health, the two subjects have not been jointly studied. There has been no focused study on how the already stressful college admissions process has been further affected by the changes brought about by the pandemic or the resultant effect on the class facing college admissions next.

To address this gap, this survey was designed with the primary aim to understand how COVID has affected stress about the college admissions cycle, and what specific pandemic-related changes have contributed to the effects on stress. Our secondary objective was to assess changed patterns in the application process amid the pandemic.

\section{Methods}

The study was conducted among the rising high school seniors (Class of 2021) across the United States from June 30th, 2020 to July 28th, 2020. A cross-sectional web-based survey was created through Google Forms with the guidance of a mentor, a research scientist in psychology. The author had informal discussions with peers before designing the survey in early June 2020 in order to better gauge issues that students were anxious or uncertain about. The Google Form was reviewed by the author's HS educators who, after approval, shared the URL link to the form along with a brief overview and rationale of the study with the class of 2021 at their school. The educators further disseminated it to peer educators across the country who likewise shared it with their own schools' class of 2021. The study was conducted among the rising high school seniors (Class of 2021) across the United States from June 30 th, 2020 to July 28th, 2020. It was an anonymous survey with online informed consent. The participation in the survey was voluntary and confidential as no personal identifiers were obtained.

The final survey consisted of 39 questions, including 29 direct and 10 conditional (based upon responses to direct questions) questions. Most questions were based on a 5-point Likert scale, ranging from strongly disagree-1 to strongly agree-5. (5-Point Likert Scale, 2010) Other question types included multiple choice and checkboxes. The survey was designed to take between 6-8 minutes to complete. The survey questions included participant demographics, such as gender, race, geographic region, and type of school attended as well as related to pertinent topics including remote learning format, standardized testing, summer plans, application support, college visitation, and financial aid as detailed below.

\section{Remote learning}

Schools across the country instituted a variety of changes in policies after the abrupt switch to remote learning and students faced unprecedented academic challenges. Our survey collected data on changes to grading policy, student perception of ability to handle the academic challenges of junior year as well as stress related to the college admissions process in general. 


\section{Standardized testing}

Advanced Placement (AP) exams give students the opportunity to demonstrate academic rigor and earn college credit. The SAT and ACT exams have long been considered essential for competitive applications. Due to the lockdown, AP exams underwent a change in format and the SAT/ACT exams were cancelled repeatedly in most of the country since lockdown in March. In response, many colleges have implemented test-optional admissions policies. We looked at the effects of these changes on students' stress as well as application patterns.

\section{Summer Plans}

Due to the lockdown, there have been extensive cancellations of service, work, research and athletic opportunities needing students to rethink their summer plans.

\section{Application Support}

The switch to a distanced format of schooling not only affected the high school Class of 2021's education and athletics, but also potentially their access to their college counselor.

\section{College Visits}

Lockdown has created a unique challenge for the class of 2021; unlike previous years these students must apply to a variety of schools without potentially having visited any.

\section{Financial Aid}

Due to widespread financial impact of the pandemic, applicants might be facing an unprecedented change in their likelihood of receiving financial support possibly changing admissions patterns in this cycle.

\section{Data Analysis}

The data gathered was analyzed and summarized using descriptive and inferential statistics, by employing SPSS for windows version 23(IBM Corp, 2015). After testing for normality, we used t-test, ANOVA and chi square to compare stress and other outcome variables among HS students based on their demographic profile, access to counselors, appearing in exams, summer plans etc. We also used Spearman's correlation wherever applied. For the analysis, all tests were conceived to be 2-tailed and the significance level was set at $\alpha=0.05$.

\section{Results}

\section{Demographic Profile of the Participants}

A total of 331 students responded to the survey, out of which $201(60.7 \%)$ were females, $119(36 \%)$ were males, and the rest $11(3.3 \%)$ preferred not to say. Majority of the participants were White (190, 57.4\%). Region wise, about $72.5 \%$ were from the Northeast followed by South (12.4\%). Majority (59\%) of the respondents were studying in public schools. (Table 1) 
Table 1. Demographic profile of the sample.

\begin{tabular}{|l|c|c|}
\hline \multicolumn{1}{|c|}{ Variables } & Frequency & \multicolumn{1}{c|}{ Percent } \\
\hline $\begin{array}{l}\text { Gender } \\
\text { Male/Female/Prefer not to say }\end{array}$ & $201 / 119 / 11$ & $60.7 \% / 36 \% / 3.3 \%$ \\
\hline $\begin{array}{l}\text { Ethnicity } \\
\text { Whites/Asians/African Americans* }\end{array}$ & $190 / 110 / 21$ & $57.4 \% / 33.3 \% / 6.3 \%$ \\
\hline $\begin{array}{l}\text { Region } \\
\text { Northeast/South/West/International }\end{array}$ & $240 / 41 / 34 / 16$ & $72.5 \% / 12.4 \% / 10.3 \% / 4.8 \%$ \\
\hline $\begin{array}{l}\text { Type of School } \\
\text { Public/ Independent boarding/ Independent day /Paro- } \\
\text { chial }\end{array}$ & $195 / 64 / 46 / 26$ & $59 \% / 19 \% / 14 \% / 8 \%$ \\
\hline
\end{tabular}

* There were 10 participants from other ethnic groups

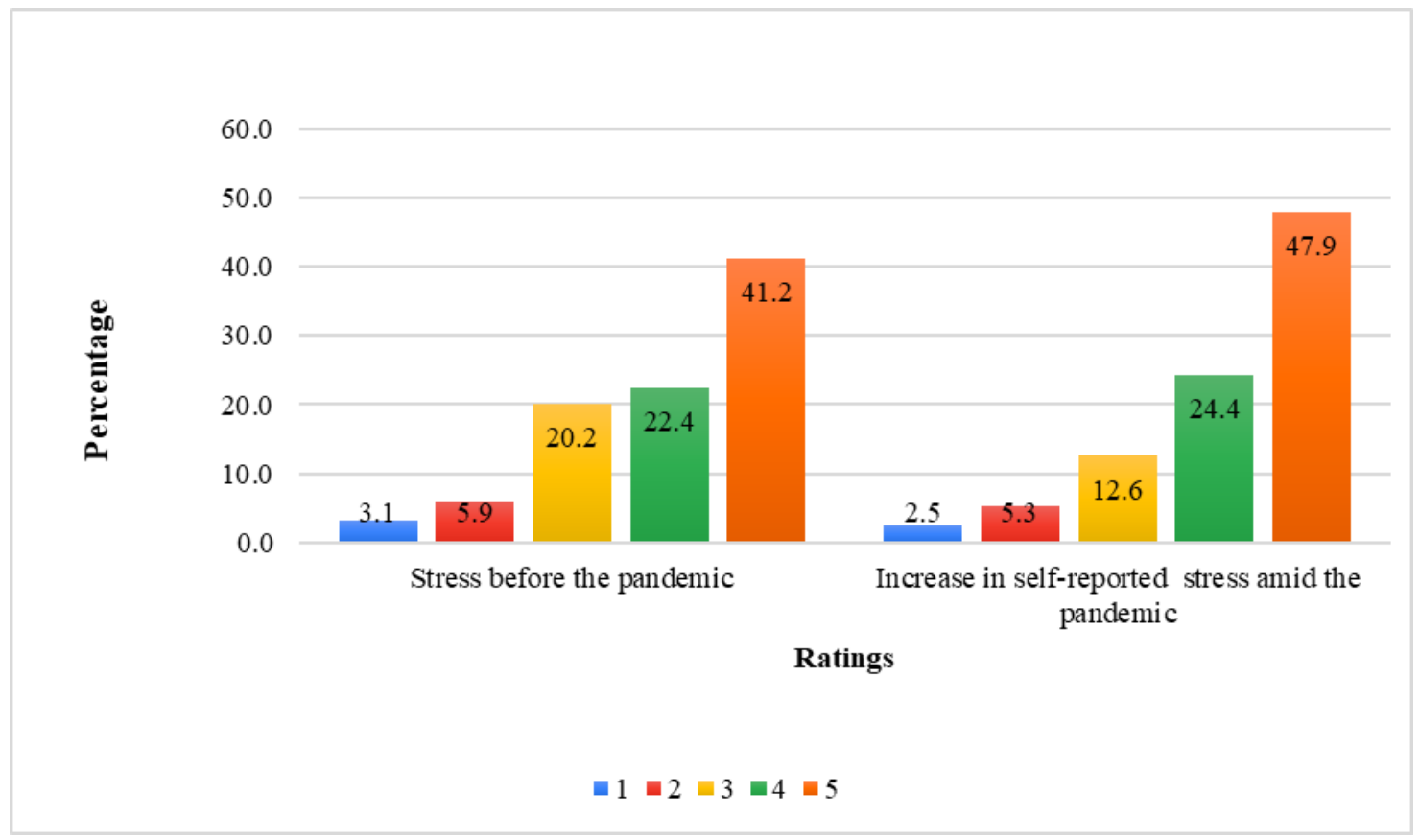

Figure 1. Stress regarding college admission process before and after the pandemic

There were two main questions regarding the college admission process; stress before pandemic and increase in self-reported stress after the pandemic. $63.6 \%$ of the survey participants stated that they were stressed about the college admissions process at the beginning of January 2020 before the pandemic. However, 72.3\% felt that their stress has increased further. We conducted correlation between students who were already stressed because of the college admissions process with those reporting an increase in stress amid the pandemic. Students already under stress perceived more increase in stress $(r=0.29, \mathrm{p}=0.01)$. 
Upon analysis of these stress patterns in relation to gender, we found significant differences between males and females. Female students reported more stress than males both in baseline stress before the pandemic ( $\mathrm{t}=22.97$, $\mathrm{p}<0.0001)$ as well as increase in stress amid the pandemic $(\mathrm{t}=23.19, \mathrm{p}<0.0001)$

No significant effect of ethnicity, US geographical region or the type of school on the level of stress was noted in our study. 59\% percent of all participants felt that the pandemic will impact their chance of going to their top choice school. Female students reported this concern more than males $(t=5.08, p=0.025)$.

\section{Handling Academic Challenges of Junior year}

We asked students regarding their ability to handle the academic challenges of junior year before and after online learning; $69.5 \%$ of the survey students stated that they were able to and $6.1 \%$ reported difficulty handling academic challenges before the pandemic. However, $60.5 \%$ reported that they were able to and $15.7 \%$ reported difficulty handling academic challenges of junior year after the pandemic.

However, on paired sample t-test there was no significant difference in handling academic challenges before and after the pandemic. We also compared males and females on handling stress using t-test but no gender differences were seen.

\section{Grading Policy}

Table 2. Change in grading policy after pandemic

\begin{tabular}{|l|l|l|}
\hline Grading Policy & Frequency & Percent \\
\hline No change in grading policy & 88 & 26.6 \\
\hline Pass/Fail & 99 & 29.9 \\
\hline Grades can only increase & 101 & 30.5 \\
\hline Change in weightage of grades & 18 & 5.4 \\
\hline Other (Optional Pass/Fail, No more grades, grade for completion etc) & 25 & 7.6 \\
\hline
\end{tabular}

There were widespread changes in grading policies with only $26.6 \%$ students reporting no change and almost three quarters reporting a variety of changes. We compared the stress levels between those who reported no change applying chi square and those who did, and found no effect of change in grading policy on stress level, both in terms of college admissions process and chance of going to top school. Grading policy changes are depicted in Table 2. 


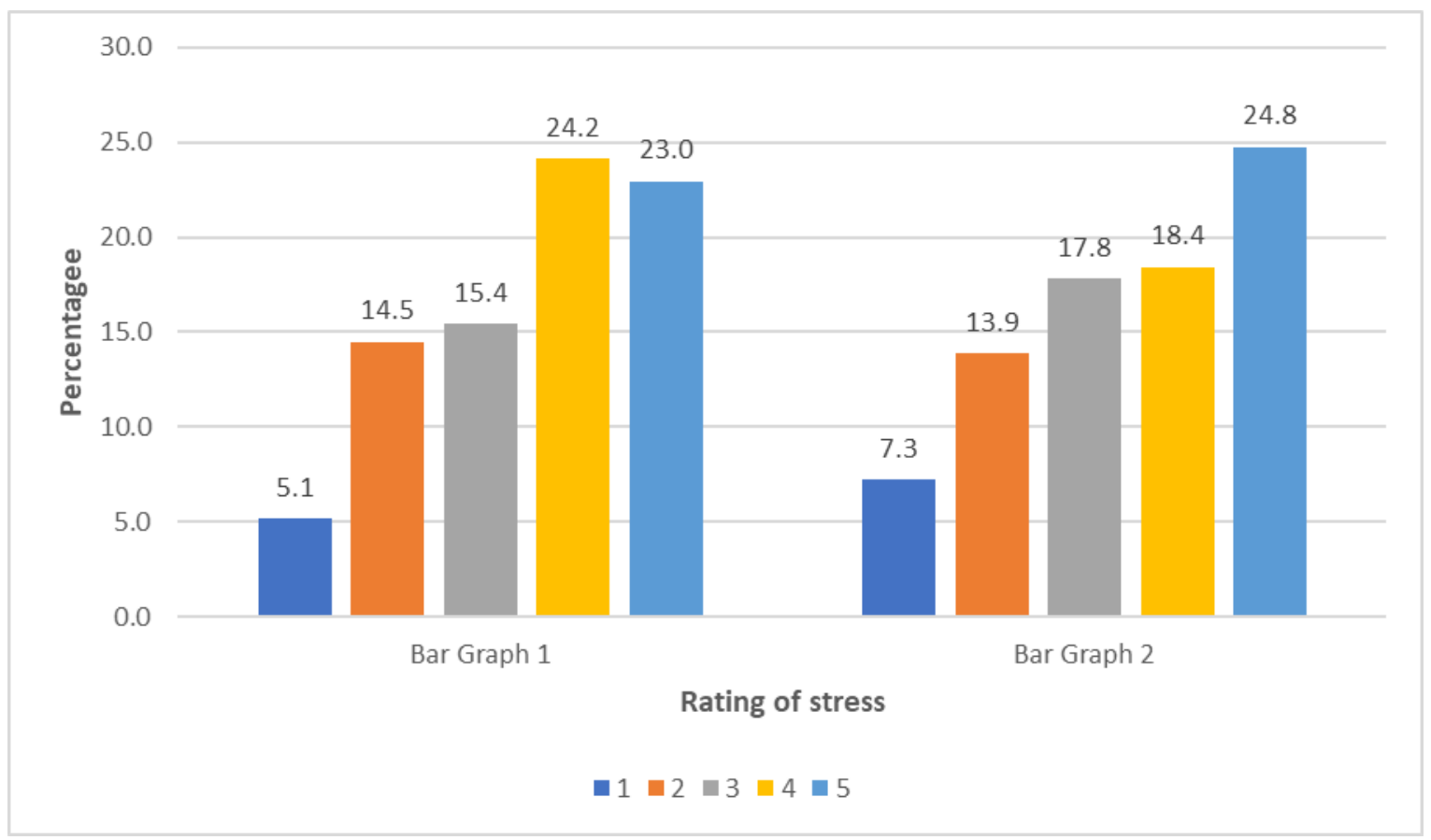

Figure 2. Stress levels of students related to the AP Exams due to the switch to online learning (Bar graph 1) and change in AP exam format (Bar graph 2)

\section{AP Exams}

About $82 \%$ students had taken one or more AP course(s) during their junior year. Out of which, $47.2 \%$ of students felt an increased stress related to preparing for AP exams due to the switch to online learning. Additionally, $43.2 \%$ of students felt an increase in stress due to change in the AP exam format.

Using Spearman correlation, there was significant negative correlation between handling of academic challenges of junior year after the pandemic with stress regarding preparing for AP exams ( $r=--0.294, p=0.0001)$ as well as stress regarding the change in AP exam format $(\mathrm{r}=-0.214, \mathrm{p}=0.0001)$. This suggested that those who felt more stressed about preparing for the AP exam and the change in AP format were less likely to handle the switch to remote learning.

\section{Standardized Testing}

Out of 331 total students 75\% (242/311) had already taken the ACT/SAT exam. 157 (65\%) students were not and 85 (35\%) were satisfied with their scores. The participants who were dissatisfied with their scores and those who had never taken were then asked whether they wanted to (re)take the test. Only $23(\sim 10 \%)$ students planned on not taking the test for the first time or again; $90 \%$ of students who had not taken or did not get their intended score planned on taking it again. 


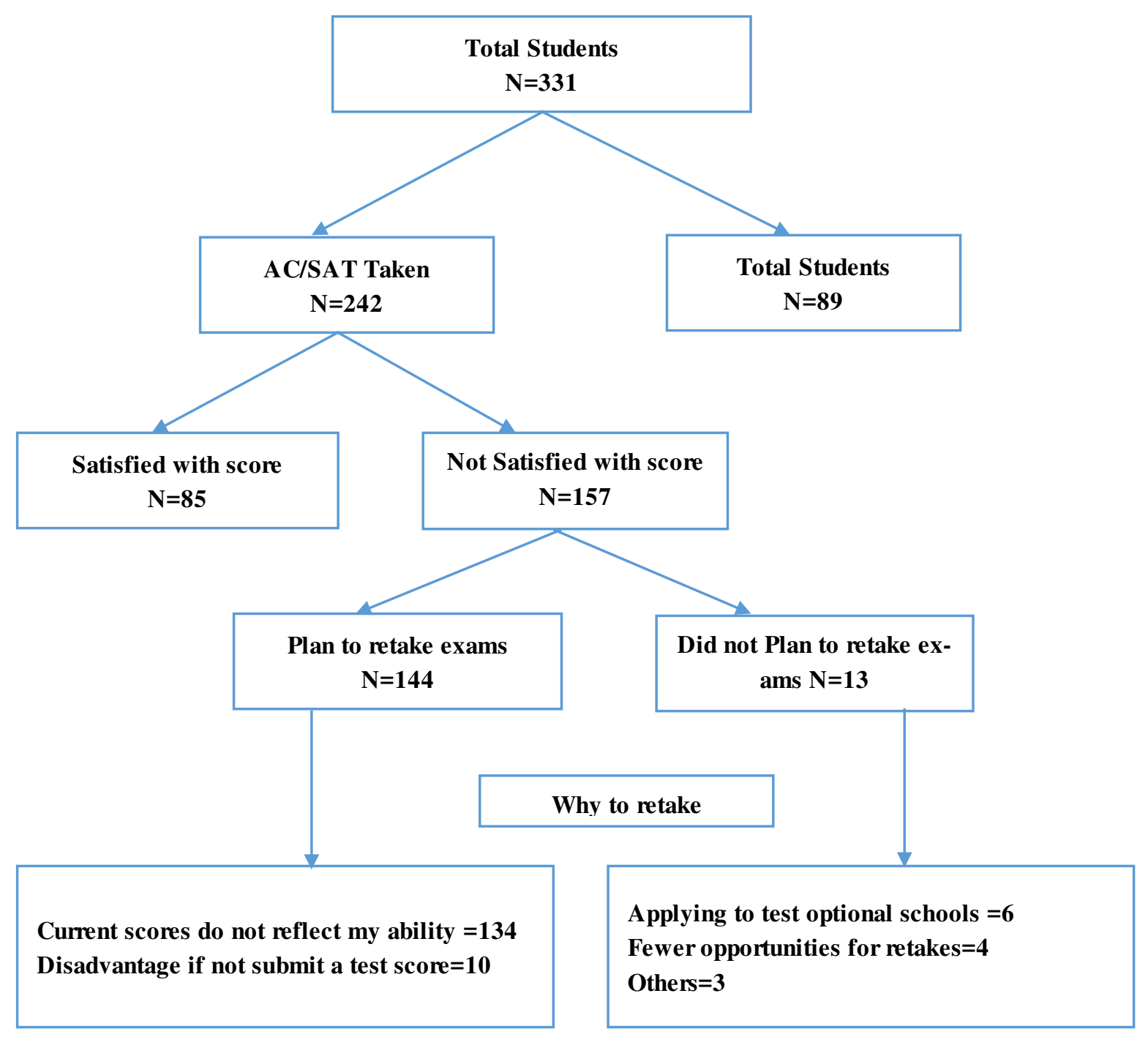

Figure 3. Flowchart of students regarding taking ACT/SAT exam.

Those who had already taken the ACT/SAT handled the stress of academic challenges after online learning better than those who had not taken the exams $(\mathrm{t}=21.22$, $\mathrm{p}<0.0001)$. However, no significant difference was noted between those who had taken and had not taken the standardized tests regarding their level of stress about the college admissions process.

\section{Summer Plans}

A large majority of participants (91.9\%) felt that pandemic has affected their pre-planned summer activities. $60.5 \%$ also felt that the change in summer plans would negatively affect the strength of their college applications.

We asked the respondents to select all applicable summer plans (see Figure 4). Majority of participants reported that they were spending time with their families and taking care of their mental and physical wellbeing. Many reported plans for activities that involved some sort of "work" including actual work, internships, service, online courses and non-school related projects. 


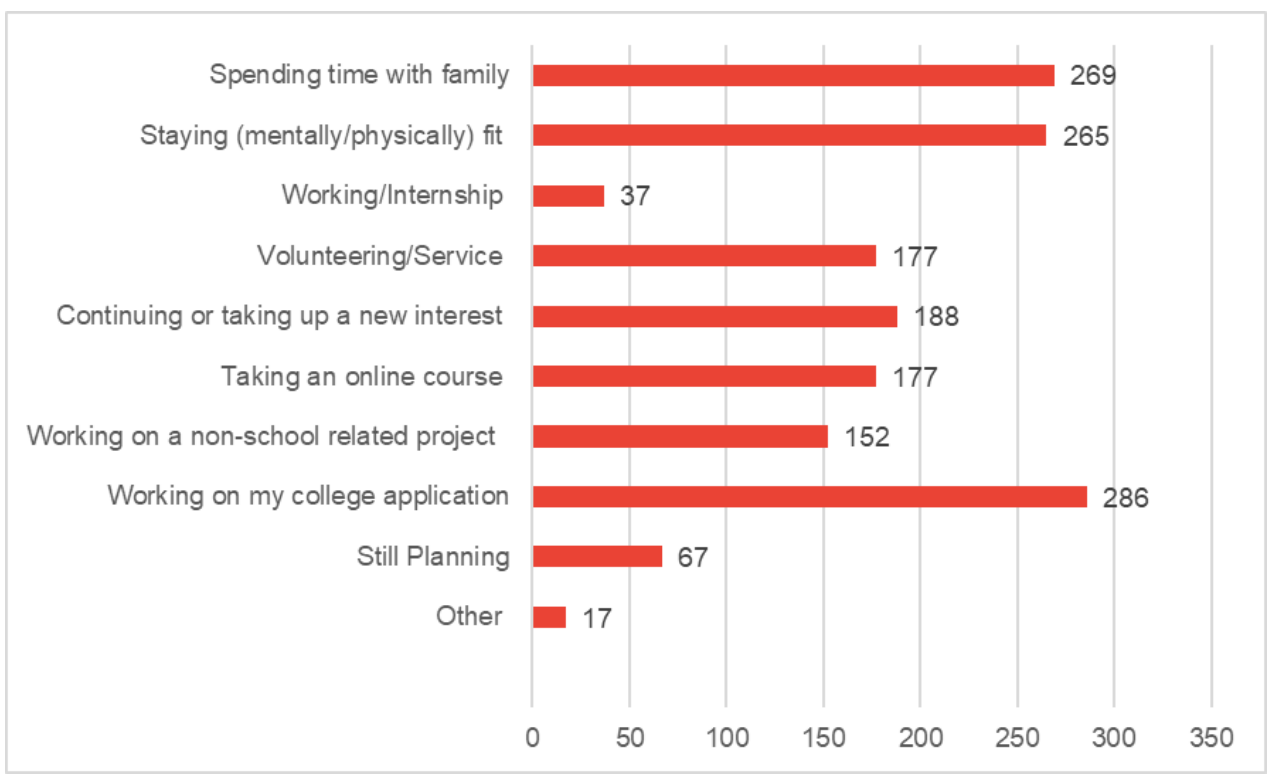

Figure 4. Plans for the summer between junior and senior year $(\mathrm{N}=331)$

We compared students with regard to the type of activities that they planned during the summer. Those who picked work related summer plans felt less pandemic effect on college applications than those who picked otherwise $(t=$ $30.53, \mathrm{p}<0.0001)$. On the contrary, those who only picked family and exercise as summer plans felt more impact on the strength of their college applications $(t=316.23, p<0.0001)$. Public school students $(\mathrm{n}=195)$ felt more of an effect of pandemic on their summer plans than students from independent and parochial schools combined. ( $\mathrm{n}=136)(\mathrm{F}$ $3,319=4.59, \mathrm{p}=0.004)$ and felt that this will impact their strength of college application $(\mathrm{F} 3,319=4.54, \mathrm{p}=0.004)$.

\section{Application Support}

Table 3. Effect of counselor communication on changes and stress regarding college admission process

\begin{tabular}{|l|l|l|l|l|l|}
\hline Communication with counselor & $\begin{array}{l}\text { Decrease } \\
\text { in commu- } \\
\text { nication } \\
(\mathbf{N = 1 3 9})\end{array}$ & $\begin{array}{l}\text { No Change } \\
\text { in communi- } \\
\text { cation } \\
(\mathbf{N = 1 6 5})\end{array}$ & $\begin{array}{l}\text { Increase } \\
\text { in } \\
\text { munica- } \\
\text { tion } \\
(\mathbf{N}=\mathbf{2 7})\end{array}$ & $\mathbf{F}_{\mathbf{2 , 3 1 9}}$ & p-value \\
\hline $\begin{array}{l}\text { Feeling of college counselor keeping student up to } \\
\text { date on changes in the admissions process } \\
(\mathrm{Mean} \pm \mathrm{SD})\end{array}$ & $2.26 \pm 1.1$ & $3.19 \pm 1.31$ & $4.07 \pm 0.86$ & 37.163 & $<0.0001$ \\
\hline
\end{tabular}


Feeling of counselor understanding student's stress regarding the admissions process due to the pandemic (Mean \pm SD)

\begin{tabular}{|l|l|l|l|l|}
\hline $2.59 \pm 1.22$ & $3.39 \pm 1.12$ & $4.36 \pm 0.83$ & 35.242 & $<0.0001$ \\
\hline
\end{tabular}

In our study, only $8 \%$ of respondents reported an increase in communication with their college counselor since the start of remote learning, $42 \%$ felt a decrease in communication and $50 \%$ did not see any change in communication.

There was a significant correlation between level of access to the counselor and the perception that the counselor was keeping the students up to date on the changes in the college admissions process and understood the students' stress regarding the same due to the pandemic $(r=0.677)$.

About $25 \%$ of students selected to contact an outside counselor; half of them had reported that their communication with their college counselors had decreased but no significant correlation between communication with a college counselor and selecting a new counselor was seen.

\section{College Visits}

Almost $90 \%$ of students have visited either none or only some of the colleges that they had planned to visit due to lockdown/quarantine. $70.2 \%$ of students felt that their inability to make onsite visits has increased their stress level about the college application cycle.

We compared students who reported stress due to inability to make on-site college visits with respect to gender and ethnicity. There was a significant difference between females (77\%) and males (59.6\%) regarding stress due to not being able to make college visits $(\chi 22=11.8, \mathrm{p}=0.003)$.

$75 \%$ of white students reported significantly more stress as compared to $62 \%$ of Asian students. $(\chi 2=11.7$, $\mathrm{p}=0.008$ ). Although $90 \%$ of African Americans were stressed, the comparison was limited by their relatively smaller number of respondents.

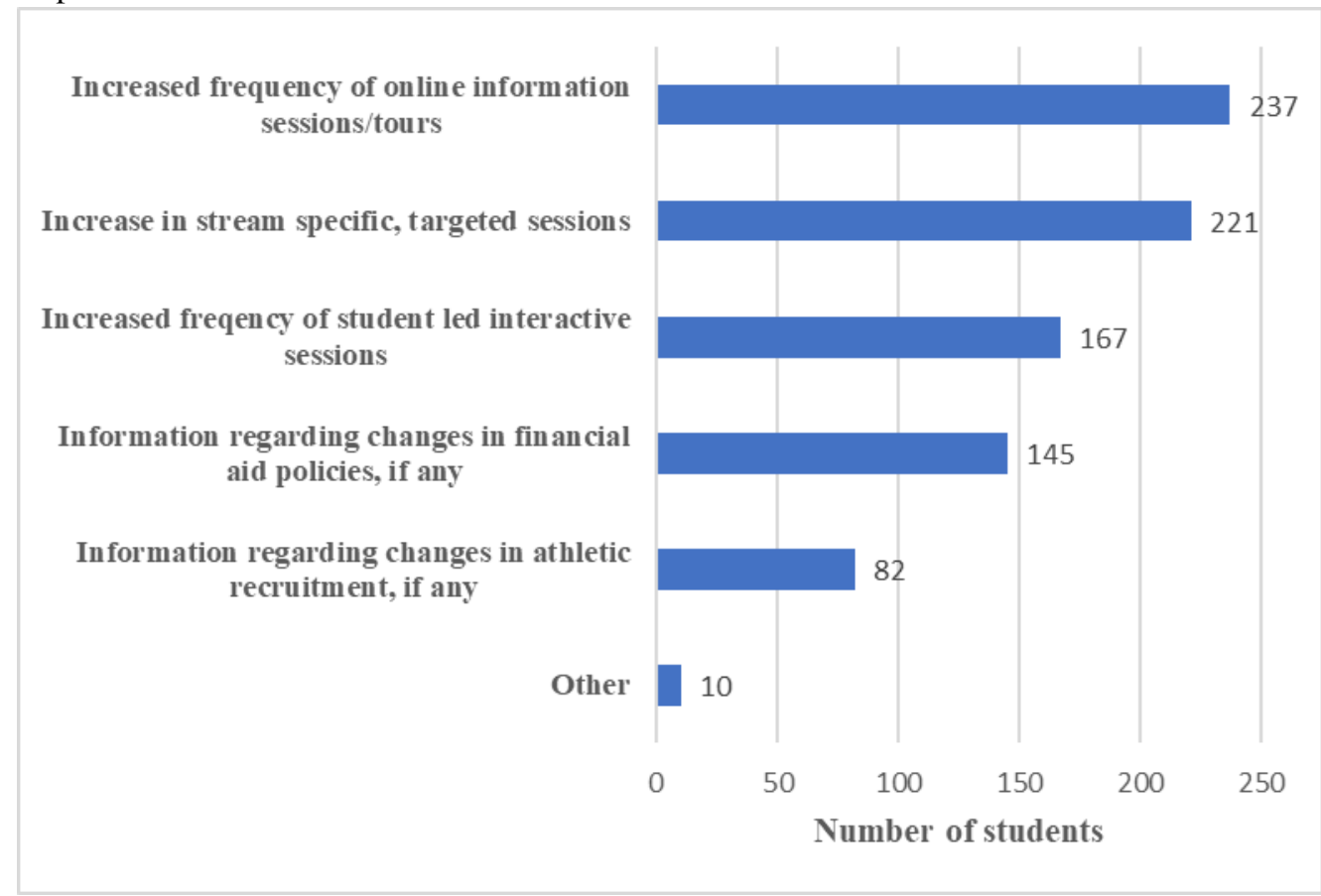

Figure 5. Desired information from college admission offices 


\section{Financial Aid}

Twenty-five percent of students felt that the pandemic had affected their family's financial situation; $35 \%$ of the respondents expressed concern about their ability to get financial aid due to the economic impact of the pandemic on colleges and universities. $\sim 60 \%$ of students reported that the potential change in financial aid policies on the colleges' part would impact their college lists.

There was significant correlation between change in family financial condition due to pandemic and concern regarding ability to obtain financial aid from educational institutions $(\mathrm{r}=0.48, \mathrm{p}<0,0001)$, and change in college list $(\mathrm{r}=0.474, \mathrm{p}<0.0001)$

\section{Athletics}

$20 \%$ of the students plan on pursuing a varsity athletic career in college; Of those students, $\sim 72 \%$ were concerned about the impact of cancellation of a junior spring (and potentially senior fall) sports season on the strength of their application.

\section{Discussion}

Our study found that the unique challenges of the COVID pandemic had a significant impact on the stress levels of HS students in relation to the college admissions process. Students, already under pressure in their junior year, the most crucial year of high school, had virtually every aspect of their lives disrupted. (Delaney, 2019, March 5) Two broad themes emerged when looking at how COVID-related changes increased stress levels and what specific factors contributed to that change: uncertainty about one's own application strength and stress due to changes in institutional policies. The first theme that emerged from our research was increased stress due to changes in factors affecting the perceived strength of the college applications. Almost $60 \%$ of respondents felt that the pandemic had directly affected their chance of going to their top choice school.

As a result of the lockdown, over $90 \%$ of our respondents felt that their pre-planned summer activities had been affected. Students often utilize their senior summers to visit colleges, start writing essays for their college applications and prep for standardized tests. (Griesemer, 2017, June 21) Additionally, they add to the strength of their application through work, internship, and research experiences. Over $60 \%$ of students felt that the cancellations of their plans would negatively impact the strength of their application, leading to an uncertainty about their college prospects. Interestingly, those who engaged in activities like volunteering, working, online courses or non-school projects compared to those who did not, felt less of an effect of the pandemic on the strength of their applications. This suggests that participating in focused productive activities helped students mitigate some of their stress regarding the disruption in their summers.

Nearly $90 \%$ of our respondents reported that they had visited none or only some of the colleges they had intended to due to the lockdown. Most students make these visits from their junior spring to senior fall which was not feasible for the class of 2021 due to campus shutdowns. A 2017 study from the Higher Education Research Institute (HERI) found that almost 50\% of college freshmen around the country found a visit to campus "very important" in deciding whether to attend the institution.(McLennan, 2019) Our results were also similar to this large study of 120,000 participants in terms of gender (female) and ethnicity (white) with regard to the importance of college visits. $60 \%$ of our respondents reported an increased stress level from not being able to make on-site visits.(McLennan, 2019) While online resources are better than nothing, they vary in quality and quantity of information and may not replicate the experience of seeing campus in-person. (Ezarik, 2020, April 20) We can infer that loss of intangibles like interaction with tour guides, a feel for the "vibe" and the "fit" of a college has led to an understandable uncertainty about where students would like to apply to. 
Of the athletes in our study, $75 \%$ were worried about the impact of cancellation of the junior spring, summer, and potentially senior fall sports seasons on the strength of their college applications. Depending on the sport, the National Collegiate Athletic Association (NCAA) reports that up to $12 \%$ of $\mathrm{HS}$ athletes play a varsity sport in college and many of them gain admission based on their athletic profile. (NCAA Research, 2020) The lack of opportunities to showcase one's talent and stats and the resultant decreased visibility to recruiters understandably led to uncertainty about their college prospects. Furthermore, as mentioned before, the lack of college visitation hampered the opportunities for interactions between athletes and college scouts.

This sentiment was shared with respondents who needed financial aid. The pandemic and nationwide shutdown has had a significant impact on the US economy. The unemployment rate hit $14.7 \%$ in April, the highest since the Great Depression with a loss of more than 20 million jobs. (Soucheray, 2020) Nearly a quarter of our respondents reported a change in their family's financial situation due to the pandemic. Additionally, colleges and universities are under financial strain due to lost revenue and higher healthcare costs, potentially leading to less availability of financial aid for students. (Kerr, 2020, March 16; Lorin, 2020, May 5) We saw a significant correlation between students who reported a change in their financial situation and those who were uncertain about receiving optimal amounts of aid. $60 \%$ of our students reported that the financial issues have affected their college lists and they might have to reconsider their options based upon the availability of financial aid.

While the first theme was an increase in stress levels due to unexpected changes affecting the perceived strength of students' applications, the second theme that emerged was related to effects on stress due to changes in institutional policies as a result of the pandemic.

With the abrupt school closures in the spring, most schools as well as students were not equipped for remote learning.(Lieberman, 2020) To mitigate the effects of this unprecedented disruption, many individual schools/districts modified their grading policies for the remainder of the year. The shift from commonly understood grading policy to a variety of alternatives might have caused a change in a students' stress regarding the admissions process. However, in our sample, this was not seen. Despite $\sim 75 \%$ of students reporting change in their schools' grading policy (Table 2 ), no correlation was seen with increased stress. An interesting idea that could be investigated further is whether grading policy changes not only do not increase the stress but may reduce it with the potential laxity of grades. This may have enduring importance as the 2020-21 school year will likely include remote learning in some form.

Standardized testing has long been a pillar of the college admissions process. Over 4.1 million students took the ACT or SAT in 2019. Because of the pandemic, the availability of these tests around the country has been low. As a response, 1450+ schools have gone test optional for this admission cycle. (Schaeffer, 2020, August 13) This was supposed to help quell stress regarding these tests and equalize the playing field for applicants, something we hypothesized that most students would take advantage of. Our respondents proved us mostly wrong. $90 \%$ of respondents who had not taken or were not satisfied with their scores wanted to (re)take the test. This suggests that students may not fully trust the college admissions offices when they declare their school to be test optional. The most overwhelming reason given for (re)taking was the perceived disadvantage of not submitting or submitting a subpar score. This speaks of the enduring nature and perceived significance of the tests in the minds of the college applicants as well as the pressure associated with submitting a subjectively less than perfect application in a highly competitive environment.

Many schools provide focused in-class preparation for AP exams, which could no longer be done effectively due to remote learning. Instead of revoking the tests, the College Board decided to change the testing format: the exams went from a 2-3 hour, physical, multisection exam to a 45-minute, 1-2 question, online format. Students enrolled in AP courses reported significant stress both due to studying for AP exams with remote learning and change in AP format. This also correlated with their self-reported difficulty handling junior year after the pandemic.

School closures significantly impacted the usual interaction between students and their counselors and our study shows that both a decreased access to the counselor and a feeling of a lack of understanding of their stress by the counselor resulted in increased stress about the college admissions process. As the college admissions process gets more competitive and complicated, HS students typically rely on their college counselors for help and guidance with their applications, recommendation letters, defining college lists, sending transcripts and completing the financial aid 
applications.(Clinedinst, 2019) The rising senior class continues to face uncertainty regarding the feasibility of onsite classes, and will likely have their first semester in a hybrid setting. Students would benefit from frequent and focused sessions with their counselors to help mitigate stress during the upcoming application period.

According to a 2010 American College Health Association report, more than 25 percent of students say that stress lowered their grades or ability to finish a course. Stress can also lead to poor and inadequate sleep, lack of concentration and potentially depression.(Carlson, 2016, September 21) Psychologists have reported that a structured schedule (like one provided in a school routine) can be coping mechanisms for young adults, especially for the vulnerable and the change of a maintained schedule might itself increase anxiety. (Lee, 2020)

Our secondary objective was to assess changes in patterns due to the pandemic. A strong majority of our respondents had visited either none or only some of the colleges on their list. This could mean that more students this year are applying to school(s) they have never visited. On the other hand, an expected change regarding students foregoing standardized tests did not happen. Despite an unprecedented switch to test optional applications, students still plan on re(taking) the tests, showing the deeply ingrained importance of doing well on these tests for gaining a college admission.

\section{Implications}

While this study only focused on a few specific aspects of the junior year experience related to the college admissions process amidst the pandemic, the implications of our results extend further.

Schools around the country need to better prepare for the upcoming school year, part or most of which will likely be a hybrid setting with increased allocation of funding for mental health resources. Uniformity in grading policies may level the playing field for applicants and ease concerns about the relative differences in the variety of grading policies. A college counselor usually has a more comprehensive view of a student than an individual teacher or a parent can have and students, particularly juniors and seniors would benefit from regularly scheduled time with their counselors.

As the pandemic progresses into the fall limiting in-person visits, colleges may need to provide more stream specific sessions, interactive guided tours, virtual 360-degree campus tours, and avenues to connect current students with applicants. These will be beneficial post-COVID too for those without the time or resources to make multiple college visits and may help equalize the college application process for all.

Even without the unusual conditions posed by the pandemic, students often find the college admission process daunting and unpredictable. This likely is the reason why an overwhelming majority of students in our survey wanted to take standardized tests despite most schools declaring that they weren't required. Acknowledging that students' applications are more than their scores and metrics, more open dialogues about the admissions process between schools and applicants would help in easing some stress related to the process, not only during the COVID era but beyond.

\section{Limitations}

While our study showed some statistically significant results, there were some limitations. Our study sample was small $(n=331)$ and the majority of the students were from the Northeast. Additionally, the distribution method of the survey might have favored specific demographics, with a disproportionate number of students from independent schools and higher average income households. Lack of randomization might have generated some bias in the study. As mentioned earlier for the case against standardized testing, these tests can favor those with more access to resources and our results may be skewed towards a higher number of students having taken them, satisfied with their scores and less stress regarding other measures like financial aid. In a larger, broader sample, the stressors for other demographics may have been potentially more pronounced. 
Also, this study by its nature was a snapshot. A longitudinal study might help both high school and college educators understand how admissions related stress changes over the span of the pandemic and better understand the implications of an increase in stress including anxiety, dropout rates, effects on schoolwork in senior year as well as positive influences like increased counselor support.

Though no significant correlation was found between the level of communication with the school counselor and consideration of an outside counselor, our small snapshot study may not have been powered to detect any emerging patterns in students seeking outside help to navigate the unprecedented and stressful college admissions process.

\section{Conclusion}

COVID-19 pandemic has affected various aspects of the crucial junior year and the upcoming college admissions process for the high school class of 2021. Students have had an increase in stress due to the unexpected changes in their academic routines, standardized testing and support from their college counselors. Uncertainty regarding securing financial aid and athletic scholarships as well as disruption of college visits for discerning the right fit have further contributed to their stress.

High school students, like most of the nation, are dealing with the toll that the pandemic is taking. At a critical point in their high school career, college applicants need various educational systems' support for them to navigate the process and join the colleges that are best suited for their career paths. This coordinated effort would benefit colleges too and help them gain a student body primed for success.

\section{Acknowledgments}

The authors gratefully acknowledge the enthusiastic participation of high school students in this survey. I am also thankful to my educators, my mom and Dr. Sonia Sethi for their guidance and support.

\section{References}

Bardi, M., Koone, T., Mewaldt, S. \& O'Connor, K. (2011). Behavioral and physiological correlates of stress related to examination performance in college chemistry students. Stress, 14(5), 557-566. doi:

$10.3109 / 10253890.2011 .571322$

Carlson, D. (2016, September 21). 3 Ways Stress Negatively Affects Student Performance.

Chang, J., Yuan, Y. \& Wang, D. (2020). [Mental health status and its influencing factors among college students during the epidemic of COVID-19]. Nan Fang Yi Ke Da Xue Xue Bao, 40(2), 171-176. doi: 10.12122/j.issn.16734254.2020.02.06

Chao, D. L., Halloran, M. E. \& Longini, I. M. (2010). School opening dates predict pandemic influenza A(H1N1) outbreaks in the United States. J Infect Dis, 202(6), 877-880. doi: 10.1086/655810

Clinedinst, M. (2019). 2019 State of college admission N. A. F. C. A. COUNSELING (Red.).

Decker, S., Peele, H. \& Riser-Kositsky, M. (2020, July 1). The Coronavirus Spring: The Historic Closing of U.S.

Schools. Education Week.

Delaney, M. (2019, March 5). Junior Year and the Importance of Staying Focused. 
Ezarik, M. (2020, April 20). Virtual college tours need storytelling component now.

Griesemer, N. (2017, June 21). Making the most of the summer before senior year. Hentet fra https://admissions.blog/making-the-most-of-the-summer-before-senior-year/

IBM Corp. (2015) IBM SPSS Statistics for Windows, Version 23.0. . Armonk, NY: IBM Corp.

Kerr, E. (2020, March 16). How the Coronavirus Can Disrupt Your College Financial Aid. U.S.News.

Lee, J. (2020). Mental health effects of school closures during COVID-19. Lancet Child Adolesc Health, 4(6), 421. doi: $10.1016 / \mathrm{S} 2352-4642(20) 30109-7$

Lieberman, M. (2020). Many Districts Won't Be Ready for Remote Learning If Coronavirus Closes Schools. Education Week, 39(25), 1, 6-7.

Lieberman, M. (2020, August 30). Schools Should Prepare for Coronavirus Outbreaks, CDC Officials Warn. Education Week.

Lorin, J. (2020, May 5). Harvard Sees \$1.2 Billion Revenue Shortfall Due to Pandemic. Bloomberg News.

Luthar, S. S. \& Becker, B. E. (2002). Privileged but pressured? A study of affluent youth. Child Dev, 73(5), 15931610. doi: $10.1111 / 1467-8624.00492$

McLennan, D. (2019). The American Freshman:National Norms Fall 2017. Research Brief, April.

NCAA Research. (2020). Estimated probability of competing in college athletics.

Schaeffer, B. (2020, August 13). Three-Fifths of Four-Year Colleges and Universities Are Test-Optional for Fall 2021 Admission; Total of Schools Not Requiring ACT/SAT Exceeds 1,450. FairTest, National Center for Fair \& Open Testing.

Soucheray, S. (2020). US job losses due to COVID-19 highest since Great Depression. Center for Infectious Disease Research and Policy (CIDRAP). 